\title{
HUBUNGAN MEDIA SOSIAL DENGAN KETERAMPILAN MENULIS PARAGRAF ARGUMENTASI MAHASISWA DI POLITEKNIK NEGERI BATAM
}

\author{
Eka Mutia Lubis \\ Jurusan Teknik Elektro, Politeknik Negeri Batam \\ Jalan Ahmad Yani, Batam Center, Kecamatan Batam Kota, Batam 2946 I \\ Email:mutia@polibatam.ac.id
}

\begin{abstract}
This study aims to determine the relationship between social media and the argumentative paragraph writing skill of Politeknik Negeri Batam students. This study employs a descriptive method, with 70 students as the research subjects. In this study, students were asked to do a practice in form of writing an argumentative paragraph. An analysis from the obtained data is then conducted to find out their mastery in composing a paragraph. As the basis for the assessment, scores in unity, coherence, and development aspect were assigned to each paragraph. These three aspects were then collected and summed up to find the mean of the data, which had been grouped and assigned score before, to determine their mastery level in writing an argumentative paragraph. Subsequently, the data were inserted into a table. Based on the table,

which recapitulates the mastery level in writing an argumentative paragraph, the results are as follows: $43 \%$ of the students have high level of mastery, with $59 \%$ of them having access to social media; 37 $\%$ of the students are in the medium level of mastery, with $28 \%$ of them having access to social media; $20 \%$ are in the low level of mastery, with $13 \%$ of them having access to social media. The results of this study show that students who are active in social media have the ability to write a good argumentative paragraph. This might be due to the fact that activities in social media enhance their writing skill, which is closely related to the four aspects of language competencies, which consist of observing, reading, listening, and writing.
\end{abstract}

Keywords: social media, argumentative paragraph, writing skills

\section{PENDAhULUAN}

Kegiatan update status di media sosial secara tidak langsung memberikan edukasi kepada mahasiswa. Media sosial seperti facebook, instagram, twitter dimanfaatkan mahasiswa untuk diskusi dan sharing terkait informasi yang mereka ketahui. Dengan mengandalkan gadget yang mereka miliki, kapan pun dan dimana pun setiap mahasiswa berlomba-lomba untuk memberikan informasi kepada pengguna media sosial tentang apa yang mereka pikirikan dan kegiatan apa yang sedang mereka lakukan. Kegiatan ini menjadi trendsetter dikalangan mileneal saat ini, mereka yang tidak aktif di media sosial justru dianggap tidak gaul atau tidak kekinian.

Kegiatan menulis di media sosial tidaklah semudah yang dipikirkan, butuh keahlian dan kebiasaan agar tulisan kita menarik untuk dibaca orang. Tulisan yang bagus bukan hanya menarik untuk dibaca tetapi juga mampu menyampaikan pesan dengan jelas, memiliki satu kesatuan dan sesuai dengan ejaan bahasa Indonesia. Dalam hal 
ini kemampuan berkomunikasi dan berbahasa sangat berperan supaya tidak terjadi kesalahan dalam penyampaian dan penyebaran informasi.

Bahasa merupakan alat menyatakan pikiran, gagasan dan maksud. Pernyataan ini diklasifikasikan secara konkret ke dalam bentuk lisan maupun tulisan. Kedua bentuk ini mempunyai kedudukan sejajar, masing-masing dengan kelebihan dan kekurangannya. Pada saat tertentu kita gunakan bentuk lisan pada saat lain mungkin lebih efektif dan efesien memakai bentuk tulisan. Memang keduanya mempunyai kedudukan sejajar, tetapi tingkat efektivitas dan tingkat efesien masing-masing sangat bersifat situasional.

Keterampilan menulis pengalaman yang memadai. Tarigan (1981:4) menyatakan, "Kegiatan menulis haruslah merupakan proses untuk membentuk suatu komunikasi tidak langsung (tidak dengan tatap muka). Kehidupan modern sekarang ini, sulit bagi orang mempercayai sesuatu apabila disampaikan secara lisan. Setiap kegiatan perlu adanya bukti tertulis (dokumen). Menulis merupakan kegiatan produktif dan ekspresif, sebab dalam prosesnya penulis barusaha mengungkapkan ide-ide atau gagasan (konsep) tertentu dengan teknik dan gaya tersendiri. Aktivitas menulis merupakan suatu aktivitas yang terencana dan membutuhkan keterampilan khusus serta menuntut pengalaman terampil menggunakan struktur kata dan kosa kata. Keterampilan menulis tidak datang dengan sendiri, melainkan latihan yang banyak dan teratur". Maka dari itu seorang penulis (mahasiswa) harus banyak berlatih, banyak menggunakan kosa kata, dan dapat menempatkan struktur kata yang baik.

Menulis paragraf merupakan salah satu keterampilan atau kemampuan menulis dalam menggunakan bahasa dan aturan-aturanya. Di dalam sebuah paragraf, biasanya terdapat sebuah kalimat yang berisikan topik sentral sedangkan kalimat lain berisi tentang penjelasan atau keterangan dari topik sentral. Menurut Keraf (2005:62) menyatakan bahwa alinea atau paragraf adalah yang terdiri dari kalimat-kalimat yang memiliki satu kesatuan pikiran yang lebih tinggi atau lebih luas dari kalimat. Gabungan kalimat-kalimat dalam suatu rangkaian untuk membentuk sebuah gagasan.

Di kampus mata kuliah bahasa Indonesia selalu diharapkan sebagai proses yang bertujuan agar mahasiswa bisa memiliki kemampuan menggunakan bahasa Indonesia dengan baik dan benar. Dari sekian banyak pembelajaran bahasa Indonesia yang diajarkan, maka salah satu diantara yang menjadi perhatian penulis adalah kemampuan menulis paragraf Argumentasi.

Keraf (2005:58) menyatakan bahwa argumentasi adalah bentuk tulisan yang ingin memengaruhi pembaca atau pendengar, agar pembaca atau pendengar itu mengubah sikap mereka, menyesuaikan dengan sikap penulis atau pengarang. Argumentasi lebih menekankan pembuktian-pembuktian atas apa yang dikatakan. Dari pendapat pakar di atas dapat kita ketahui bahwa karangan argumentasi ialah karangan yang berisi pendapat yang disertai pembahasan dan diperkuat dengan fakta-fakta sehingga pendapat itu diterima kebenarannya. Selain itu di dalam karangan argumentasi penulis harus berusaha meyakinkan orang lain atau pembaca, terus berusaha membuktikan kebenaran suatu pernyataan atau pokok permasalahan di dalam karangan argumentasi, dan penulis juga harus dapat mengubah pendapat pembaca terhadap karangan argumentasi yang dibacanya. Penulis juga harus menampilkan fakta yang merupakan bahan pembuktian terhadap kebenaran suatu argumentasi.

Mahasiswa sering menganggap kegiatan menulis adalah tugas yang berat dalam belajar, terutama bagi mahasiswa yang kurang minatnya pada materi belajar menulis paragraf. Anggapan tersebut karena dalam menulis paragraf, mahasiswa kurang memiliki kosa kata, daya nalar, dan perhatian yang sungguh-sungguh dalam proses pembelajaran. 
Mahasiswa kurang memiliki kosa kata dan daya nalar atau kemampuan berpikir disebabkan oleh kurang banyak membaca. Pengembangan kemampuan berpikir dapat dilakukan lewat program membaca. Dengan membaca siswa dapat berpikir kritis. Membaca ini dikembangkan berdasarkan asumsi bahwa anak-anak dapat berpikir, bertindak dengan sadar, menyelidik, menggunakan pengalaman dan pengetahuannya, menilai fakta dan menarik kesimpulan berdasarkan fakta-fakta, dan menghakimi atau membuat keputusan. Selain itu mereka terlibat secara emosional, memiliki berbagai minat, mampu belajar, dan mampu memahami sesuatu. Maka dari itu jika mahasiswa memiliki kemampuan daya nalar atau berpikir yang kritis mahasiswa dengan mudah menulis paragraf.

\section{Landasan Teori}

Syarat utama yang harus diperhatikan dalam menulis paragraf adalah kesatuan dalam mengembangkan paragraf sehingga menjadi paragraf yang utuh dan jelas. Semi (1995:105) menyatakan bahwa setiap paragraf harus mengandung satu pokok pikiran. Hal ini berarti tidak boleh ada dalam satu paragraf mengandung satu pokok pikiran. Kalau terdapat dua atau lebih pokok pikiran, maka masing-masing pokok pikiran dituangkan dalam paragraf tersendiri. Menurut Arifin dan S. Amran (2006:127) kesatuan adalah dalam sebuah paragraf terdapat hanya satu pokok pikiran. Oleh sebab itu, kalimat-kalimat yang membentuk paragraf perlu ditata secara cermat agar tidak ada satupun kalimat yang meyimpang dari ide pokok paragraf itu. Kalau ada kalimat yang menyimpang dari pokok pikiran paragraf itu, paragraf menjadi tidak berpautan atau tidak utuh.

Sementara itu, menurut Nasucha, Yakub dkk (2006: 35-36) tiap paragraf mengandung satu gagasan pokok atau satu topik. Fungsi paragraf ialah mengembangkan topik tersebut. Oleh karena itu, dalam pengembangannya tidak boleh terdapat unsur-unsur yang samasekali tidak berhubungan dengan topik atau gagasan pokok tersebut. Penyimpangan akan menyulitkan pembaca. Jadi, satu paragraf hanya boleh mengandung satu gagasan pokok atau topik. Semua kalimat dalam paragraf harus membicarakan gagasan pokok tersebut.

Paragraf dianggap mempunyai kesatuan, jika kalimat-kalimat dalam paragraf itu tidak terlepas dari topiknya atau selalu relevan dengan topik. Semua kalimat terfokus pada topik dan mencegah masuknya hal-hal yang tidak relevan. Berdasarkan uraian tersebut, dapat disimpulkan bahwa kesatuan adalah setiap paragraf hanya mengandung satu gagasan pokok atau ide pokok. Maka, kalimat-kalimat yang membina paragraf itu tidak ada yang menyimpang dari gagasan pokok atau ide pokok.

\section{Kepaduan}

Syarat kedua yang harus dipenuhi oleh sebuah paragraf ialah koherensi atau kepaduan. Satu paragraf bukanlah merupakan kumpulan atau tumpukan kalimat yang masing-masing berdiri sendiri atau terlepas, tetapi dibangun oleh kalimat-kalimat yang mempunyai hubungan timbal balik.

Faizah (2007:80) menyatakan bahwa kepaduan atau koherensi adalah adanya hubungan yang harmonis yang memperlihatkan kesatuan kebersamaan antara satu kalimat dengan kalimat lainnya dalam sebuah alinea. Menurut Arifin dan S. Amran (2006:127) kepaduan paragraf dapat dilihat melalui penyusunan kalimat secara logis dan melalui ungkapan-ungkapan (kata-kata) pengait antar `kalimat. Urutan yang logis akan terlihat dalam susunan kalimat dalam paragraf itu. Dalam paragraf itu tidak ada kalimat-kalimat yang sumbang atau keluar dari permasalahan yang ada.

Menurut Charlina dan Mangatur (2008:69) paragraf yang padu disebut juga paragraf yang koherensi. Sebuah paragraf dikatakan koheren, apabila ada kekompakan antara gagasan yang dikemukakan antara kalimat yang satu dengan kalimat yang lainnya. Kalimat-kalimat dalam paragraf yang koheren memiliki hubungan timbal balik serta 
secara bersama-sama membahas satu gagasan utama. Tidak dijumpai satupun kalimat yang menyimpang ataupun loncatan-loncatan pikiran yang membingungkan.

Kepaduan atau koherensi dititikberatkan pada hubungan antar kalimat dengan kalimat. Pembaca dapat dengan mudah memahami dan mengikuti jalan pikiran penulis tanpa hambatan karena adanya loncatan pikiran yang membingungkan. Urutan pikiran yang teratur, akan memperhatikan adanya kepaduan.

Berdasarkan pendapat beberapa ahli di atas, maka penulis menyimpulkan kepaduan berhubungan erat dengan kelogisan antara kalimat-kalimat yang membentuk paragraf itu. Dalam paragraf tersebut terdapat kekompakan hubungan antara sebuah kalimat dengan kalimat yang lain.

\section{Pengembangan}

Penulis dituntut untuk kreatif mengembangkan ide menjadi paragraf yang baik sesuai dengan syarat-syarat paragraf yaitu kesatuan, kepaduan dan pengembangan paragraf. Yang dimaksud dengan kelengkapan (perkembangan) adalah penyusuan perincian daripada gagasan yang membina paragraf itu. Paragraf akan baik apabila penulis dapat mengembangkan kalimat pokok kedalam kalimat-kalimat penjelas ( Hakim 2007:357).

Menurut Charlina dan Mangatur (2008:74) pengembangan paragraf adalah pengembangan kalimat topik ke dalam kalimat-kalimat pengembang. Dengan demikian, pengembangan paragraf membutuhkan persyaratan, yakni pengembangan gagasan dasar ke dalam gagasan pengembang atau sejumlah gagasan pengembang. Gagasan dasar diungkapkan ke dalam kalimat topik dan gagasan-gagasan pengembang diungkapkan dalam kalimat-kalimat pengembang.

Pengembangan paragraf terwujud atau terpenuhi jika kalimat topik sudah dilengkapi dengan kalimat-kalimat pengembang. Adanya kalimat atau sejumlah kalimat pengembang menjadi petunjuk bahwa pengembangan paragraf sudah dilakukan oleh penulis. Paragraf yang baik adalah paragraf yang mengandung gagasan dasar dan sejumlah gagasan pengembang.

Berdasarkan uraian tersebut, maka penulis menyimpulkan pengembangan paragraf adalah bagaimana mengembangkan ide pokok menjadi sebuah paragraf yang didukung oleh kalimat penjelas yang relevan.

\section{METODE}

Penelitian ini melibatkan 70 subjek, yaitu mahasiswa baru di Politeknik Negeri Batam pada semester genap TA 2018/2019. Subjek penelitian ini adalah mahasiswa yang mengambil mata kuliah Bahasa Indonesia dan mahasiswa ini memiliki akun di media sosial. Data dikumpulkan melalui tes menulis sebuah paragraf. Data paragraf argumentasi terdiri atas aspek kesatuan, kepaduan, dan pengembangan paragraf yang terdiri atas satu paragraf. Paragraf minimal terdiri atas lima kalimat.

\section{Sumber Data}

Penelitian ini menggunakan metode deskriptif. Metode ini bertujuan menjelaskan atau menguraikan suatu masalah dengan apaadanya (objektif). Metode deskriptif adalah penelitian status sekelompok manusia, suatu objek, suatu kondisi, suatu sistem pemikiran ataupun kelas peristiwa pada masa sekarang. Di mana tujuan penelitian deskriptif adalah membuat deskripsi, gambaran, atau lukisan secara sistematis, faktual dan akurat mengenai fakta dan sifatsifat serta fenomena hubungan antara fenomena yang diselidiki.( Nazir, 1998:63)

Metode deskriptif adalah suatu metode yang bersifat pengumpulan, pengolahan, dan pengklasifikasian data. Penelitian memaparkan subjek dan objek penelitian yang didasarkan pada fakta dan data sehingga pemberian gambaran yang objektif tentang fakta dan data yang didapat di lapangan. Data-data tersebut kemudian dianalisis 
dengan menggunakan perhitungan sesuai dengan tujuan penelitian sehingga diperolehlah hasil penelitian yang akurat.

\section{Cara Memperoleh Data}

Data dinilai berdasarkan jenis permasalahan. Setelah data diperoleh mengenai keterampilan menulis paragraf argumentasi maka data tersebut dianalisis. Cara mengukur ketrampilan menulis setiap mahasiswa dengan mengadakan penyekoran yang disesuaikan dengan metode analisis, yaitu dengan memberi nilai pada aspek kesatuan, kepaduan dan pengembangan. Berdasarkan metode penelitian maka ditetapkan nilai setiap aspek maksimal 50 maka dijumlahkan menjadi 150.

Untuk Menentukan kemampuan menulis paragraf argumentasi penulis menggunakan rumus:

$$
\begin{array}{ll}
\mathrm{KMPA}=\left(\sum \mathrm{SB} / \mathrm{ST}\right) \times 100 \% & \\
\text { Keterangan: } & \\
\mathrm{KMPA}= & \text { kemampuan menulis paragraf argumentasi } \\
\sum \mathrm{SB}= & \text { jumlah skor benar } \\
\mathrm{ST} \quad= & \text { jumlah skor total/maksimal } \\
(\text { Razak, 2007:19) } &
\end{array}
$$

Mahasiswa dikatakan mampu menuliskan paragraf apabila memperoleh nilai 80-100, sedangkan mahasiswa yang memperoleh nilai di bawah 50 dikatakan kurang. Cara untuk menganalisis data dan menghitung nilai ratarata siswa yang diperoleh dari hasil tes menggunakan rumus:

$$
\begin{array}{lll}
\bar{x} \quad= & \left(\sum \mathrm{Xi}\right) / \mathrm{n} \\
\text { Keterangan: } & \\
\bar{x} \quad= & \text { nilai rata-rata } \\
\sum \mathrm{Xi}= & \text { jumlah nilai siswa secara keseluruhan } \\
\mathrm{N} \quad= & \text { jumlah siswa }
\end{array}
$$

(Razak, 2005:38)

Berdasarkan sejumlah data yang dipaparkan selanjutnya penulis akan menganalisis data hasil penelitian. Dimulai dengan analisis penguasaan dalam pembuatan paragraf argumentsi. Analisis tersebut dimaksudkan untuk mengetahui bagaimana gambaran atau keadaan yang sebenarnya, taraf penguasaan mahasiswa tersebut dalam membuat paragraf argumentasi. Sebelum data sampel dianalisis terlebih dahulu, ditentukan kriteria-kriteria penilaian untuk kemampuan menulis paragraf argumentasi. Kriteria-kriteria tersebut digunakan untuk mengetahui tingkat kemampuan siswa. Kriteria-kriteria yang dimaksud adalah:

Tabel 1.Pedoman Penilaian Menurut Kurikulum

\begin{tabular}{|c|l|c|c|}
\hline \multirow{2}{*}{ No } & \multirow{2}{*}{ Bentuk Kualitatif } & \multicolumn{2}{|c|}{ Bentuk Kuantitatif } \\
\cline { 3 - 4 } & & Rentang 0-10 & Rentang 0-100 \\
\hline 1 & Istimewa & 10 & $96-100$ \\
\hline 2 & Baik sekali & 9 & $86-95$ \\
\hline 3 & Baik & 8 & $76-85$ \\
\hline 4 & Cukup & 7 & $66-75$ \\
\hline 5 & Sedang & 6 & $56-65$ \\
\hline 6 & Kurang & 5 & $46-55$ \\
\hline
\end{tabular}




\begin{tabular}{|l|l|c|c|}
\hline 7 & Kurang sekali & 4 & $36-45$ \\
\hline
\end{tabular}

(Kemenristekdikti, 2016)

Pedoman penelitian tersebut terdiri dari tujuh kriteria. Dalam penelitian ini, pedoman penelitian ini penulis sederhanakan menjadi tiga kriteria. Maka, kategori istimewa, baik sekali, dan baik digolongkan tinggi. Kategori cukup dan sedang digolongkan sedang. Sedangkan kategori kurang dan kurang sekali digolongkan rendah.Untuk lebih jelasnya dapat dilihat pada tabel berikut:

Tabel 2 Pedoman Penilaian Pengolahan Data

\begin{tabular}{|c|c|c|}
\hline No & Bentuk Kualitatif & Bentuk Kuantitatif \\
\hline 1 & Tinggi & $80-100$ \\
\hline 2 & Sedang & $60-79$ \\
\hline 3 & Rendah & $40-59$ \\
\hline
\end{tabular}

\section{HASIL DAN PEMBAHASAN}

Kemampuan menulis paragraf argumentasi mahasiswa Politeknik Negeri Batam ini diperoleh dari nilai aspek kesatuan, kepaduan, dan pengembangan paragraf. Ketiga aspek tersbut digabungkan, dijumlahkan, selanjutnya dirata-ratakan. Sehingga diperoleh data tingkat ketrampilan menulis paragraf argumentasi yang telah dinilai dan diklasifikasikan. Data tersebut dapat dilihat pada tabel berikut ini:

Tabel 3 Rekapitulasi Keterampilan Menulis Paragraf Argumentasi Mahasiswa Politeknik Negeri Batam

\begin{tabular}{|c|c|c|c|c|c|c|c|c|c|c|c|}
\hline \multirow{2}{*}{ No } & \multirow{2}{*}{$\mathrm{KR}$} & \multirow{2}{*}{ JK } & \multirow{2}{*}{$\mathrm{KP}$} & \multirow{2}{*}{ ST } & \multicolumn{3}{|c|}{ Nilai } & \multirow{2}{*}{ Jumlah } & \multirow{2}{*}{ Persentase } & \multirow{2}{*}{ Kategori } & \multirow{2}{*}{$\begin{array}{c}\text { Akses } \\
\text { Medsos }\end{array}$} \\
\hline & & & & & Ks & $\mathrm{Kp}$ & $\mathrm{P}$ & & & & \\
\hline 1 & 01 & $\mathrm{P}$ & I AB3 & 150 & 50 & 50 & 50 & 150 & 100 & Tinggi & Tinggi \\
\hline 2 & 06 & $\mathrm{P}$ & I AB2 & 150 & 50 & 50 & 50 & 150 & 100 & Tinggi & Tinggi \\
\hline 3 & 08 & $\mathrm{P}$ & I AB2 & 150 & 50 & 50 & 50 & 150 & 100 & Tinggi & Tinggi \\
\hline 4 & 14 & $\mathrm{P}$ & I AB3 & 150 & 50 & 50 & 50 & 150 & 100 & Tinggi & Tinggi \\
\hline 5 & 21 & $\mathrm{P}$ & I AB4 & 150 & 50 & 50 & 50 & 150 & 100 & Tinggi & Tinggi \\
\hline 6 & 22 & $\mathrm{P}$ & I AB4 & 150 & 50 & 50 & 50 & 150 & 100 & Tinggi & Tinggi \\
\hline 7 & 09 & $\mathrm{~L}$ & I AB2 & 150 & 50 & 50 & 50 & 150 & 100 & Tinggi & Tinggi \\
\hline 8 & 23 & $P$ & I AB4 & 150 & 50 & 50 & 50 & 150 & 100 & Tinggi & Tinggi \\
\hline 9 & 24 & $\mathrm{P}$ & I AB4 & 150 & 50 & 50 & 50 & 150 & 100 & Tinggi & Tinggi \\
\hline 10 & 25 & $\mathrm{P}$ & I AB4 & 150 & 50 & 50 & 50 & 150 & 100 & Tinggi & Tinggi \\
\hline 11 & 29 & $\mathrm{P}$ & I AB1 & 150 & 50 & 50 & 50 & 150 & 100 & Tinggi & Tinggi \\
\hline 12 & 31 & $\mathrm{P}$ & I AB2 & 150 & 50 & 50 & 50 & 150 & 100 & Tinggi & Tinggi \\
\hline 13 & 32 & $\mathrm{P}$ & I AB3 & 150 & 50 & 50 & 50 & 150 & 100 & Tinggi & Tinggi \\
\hline 14 & 33 & $\mathrm{P}$ & I AB3 & 150 & 50 & 50 & 50 & 150 & 100 & Tinggi & Tinggi \\
\hline 15 & 34 & $\mathrm{P}$ & I AB3 & 150 & 50 & 50 & 50 & 150 & 100 & Tinggi & Tinggi \\
\hline 16 & 35 & $\mathrm{P}$ & I AB3 & 150 & 50 & 50 & 50 & 150 & 100 & Tinggi & Tinggi \\
\hline 17 & 39 & $\mathrm{P}$ & I AB1 & 150 & 50 & 50 & 50 & 150 & 100 & Tinggi & Tinggi \\
\hline 18 & 42 & $\mathrm{P}$ & I AB4 & 150 & 50 & 50 & 50 & 150 & 100 & Tinggi & Tinggi \\
\hline
\end{tabular}




\begin{tabular}{|c|c|c|c|c|c|c|c|c|c|c|c|}
\hline 19 & 47 & $\mathrm{P}$ & I AB4 & 150 & 50 & 50 & 50 & 150 & 100 & Tinggi & Tinggi \\
\hline 20 & 40 & $\mathrm{~L}$ & I AB 1 & 150 & 50 & 50 & 50 & 150 & 100 & Tinggi & Tinggi \\
\hline 21 & 66 & $\mathrm{~L}$ & I AB1 & 150 & 50 & 50 & 50 & 150 & 100 & Tinggi & Tinggi \\
\hline 22 & 51 & $\mathrm{P}$ & I AB1 & 150 & 50 & 50 & 40 & 140 & 93,33 & Tinggi & Tinggi \\
\hline 23 & 56 & $\mathrm{P}$ & I AB1 & 150 & 50 & 50 & 40 & 140 & 93,33 & Tinggi & Tinggi \\
\hline 24 & 36 & $\mathrm{P}$ & I AB3 & 150 & 50 & 40 & 40 & 130 & 86,67 & Tinggi & Tinggi \\
\hline 25 & 41 & $\mathrm{P}$ & I AB4 & 150 & 50 & 40 & 40 & 130 & 86,67 & Tinggi & Tinggi \\
\hline 26 & 67 & $\mathrm{P}$ & I AB4 & 150 & 40 & 50 & 40 & 130 & 86,67 & Tinggi & Tinggi \\
\hline 27 & 58 & $\mathrm{P}$ & I AB1 & 150 & 40 & 30 & 50 & 120 & 80 & Tinggi & Tinggi \\
\hline 28 & 04 & $\mathrm{P}$ & I AB1 & 150 & 40 & 40 & 40 & 120 & 80 & Tinggi & Tinggi \\
\hline 29 & 16 & $\mathrm{P}$ & I AB2 & 150 & 40 & 40 & 40 & 120 & 80 & Tinggi & Tinggi \\
\hline 30 & 68 & $\mathrm{~L}$ & I AB4 & 150 & 40 & 40 & 40 & 120 & 80 & Tinggi & Tinggi \\
\hline 31 & 53 & $\mathrm{P}$ & I AB 1 & 150 & 40 & 40 & 30 & 110 & 73,33 & Sedang & Tinggi \\
\hline 32 & 61 & $\mathrm{P}$ & I AB1 & 150 & 40 & 30 & 40 & 110 & 73,33 & Sedang & Tinggi \\
\hline 33 & 70 & $\mathrm{~L}$ & I AB1 & 150 & 40 & 40 & 30 & 110 & 73,33 & Sedang & Tinggi \\
\hline 34 & 03 & $\mathrm{~L}$ & I AB2 & 150 & 30 & 30 & 30 & 90 & 60 & Sedang & Tinggi \\
\hline 35 & 07 & $\mathrm{P}$ & I AB4 & 150 & 30 & 30 & 30 & 90 & 60 & Sedang & Tinggi \\
\hline 36 & 10 & $\mathrm{P}$ & I AB2 & 150 & 30 & 30 & 30 & 90 & 60 & Sedang & Tinggi \\
\hline 37 & 13 & $\mathrm{~L}$ & I AB3 & 150 & 30 & 30 & 30 & 90 & 60 & Sedang & Tinggi \\
\hline 38 & 15 & $\mathrm{~L}$ & I AB3 & 150 & 30 & 30 & 30 & 90 & 60 & Sedang & Tinggi \\
\hline 39 & 17 & $\mathrm{P}$ & I AB3 & 150 & 30 & 30 & 30 & 90 & 60 & Sedang & Tinggi \\
\hline
\end{tabular}

Tabel 3 (Lanjutan)

\begin{tabular}{|c|c|c|c|c|c|c|c|c|c|c|c|}
\hline 40 & 18 & P & I AB2 & 150 & 30 & 30 & 30 & 90 & 60 & Sedang & Sedang \\
\hline 41 & 19 & P & I AB2 & 150 & 30 & 30 & 30 & 90 & 60 & Sedang & Sedang \\
\hline 42 & 20 & P & I AB3 & 150 & 30 & 30 & 30 & 90 & 60 & Sedang & Sedang \\
\hline 43 & 26 & L & I AB2 & 150 & 30 & 30 & 30 & 90 & 60 & Sedang & Sedang \\
\hline 44 & 27 & P & I AB4 & 150 & 30 & 30 & 30 & 90 & 60 & Sedang & Sedang \\
\hline 45 & 30 & P & I AB1 & 150 & 30 & 30 & 30 & 90 & 60 & Sedang & Sedang \\
\hline 46 & 37 & P & I AB3 & 150 & 30 & 30 & 30 & 90 & 60 & Sedang & Sedang \\
\hline 47 & 38 & P & I AB1 & 150 & 30 & 30 & 30 & 90 & 60 & Sedang & Sedang \\
\hline 48 & 43 & P & I AB4 & 150 & 30 & 30 & 30 & 90 & 60 & Sedang & Sedang \\
\hline 49 & 44 & P & I AB4 & 150 & 30 & 30 & 30 & 90 & 60 & Sedang & Sedang \\
\hline 50 & 45 & P & I AB4 & 150 & 30 & 30 & 30 & 90 & 60 & Sedang & Sedang \\
\hline 51 & 49 & P & I AB1 & 150 & 30 & 30 & 30 & 90 & 60 & Sedang & Sedang \\
\hline 52 & 50 & P & I AB1 & 150 & 30 & 30 & 30 & 90 & 60 & Sedang & Tinggi \\
\hline 53 & 52 & P & I AB1 & 150 & 30 & 30 & 30 & 90 & 60 & Sedang & Tinggi \\
\hline 54 & 62 & P & I AB3 & 150 & 30 & 30 & 30 & 90 & 60 & Sedang & Sedang \\
\hline 55 & 63 & P & I AB1 & 150 & 30 & 30 & 30 & 90 & 60 & Sedang & Sedang \\
\hline
\end{tabular}




\begin{tabular}{|c|c|c|c|c|c|c|c|c|c|c|c|}
\hline 56 & 64 & $\mathrm{P}$ & I AB2 & 150 & 30 & 30 & 30 & 90 & 60 & Sedang & Sedang \\
\hline 57 & 55 & $\mathrm{P}$ & I AB1 & 150 & 40 & 20 & 20 & 80 & 53,33 & Rendah & Rendah \\
\hline 58 & 46 & $\mathrm{P}$ & I AB4 & 150 & 20 & 30 & 20 & 70 & 46,67 & Rendah & Sedang \\
\hline 59 & 54 & $\mathrm{P}$ & I AB1 & 150 & 30 & 20 & 20 & 70 & 46,67 & Rendah & Sedang \\
\hline 60 & 69 & $\mathrm{~L}$ & I AB2 & 150 & 30 & 10 & 30 & 70 & 46,67 & Rendah & Sedang \\
\hline 61 & 12 & $\mathrm{~L}$ & I AB2 & 150 & 20 & 20 & 20 & 60 & 40 & Rendah & Rendah \\
\hline 62 & 48 & $\mathrm{P}$ & I AB1 & 150 & 20 & 20 & 20 & 60 & 40 & Rendah & Rendah \\
\hline 63 & 57 & $\mathrm{P}$ & I AB1 & 150 & 20 & 20 & 20 & 60 & 40 & Rendah & Rendah \\
\hline 64 & 59 & $\mathrm{~L}$ & I AB2 & 150 & 20 & 20 & 20 & 60 & 40 & Rendah & Rendah \\
\hline 65 & 60 & $\mathrm{P}$ & I AB1 & 150 & 20 & 20 & 20 & 60 & 40 & Rendah & Rendah \\
\hline 66 & 02 & $\mathrm{~L}$ & I AB2 & 150 & 20 & 20 & 20 & 60 & 40 & Rendah & Sedang \\
\hline 67 & 05 & $\mathrm{P}$ & I AB2 & 150 & 20 & 20 & 20 & 60 & 40 & Rendah & Sedang \\
\hline 68 & 11 & $\mathrm{P}$ & I AB2 & 150 & 20 & 20 & 20 & 60 & 40 & Rendah & Rendah \\
\hline 69 & 28 & $\mathrm{~L}$ & I AB4 & 150 & 20 & 20 & 20 & 60 & 40 & Rendah & Rendah \\
\hline 70 & 65 & $\mathrm{P}$ & I AB4 & 150 & 20 & 20 & 20 & 60 & 40 & Rendah & Rendah \\
\hline \multicolumn{4}{|c|}{ Jumlah } & 10500 & 2580 & 2510 & 2500 & 7590 & 5020 & & \\
\hline \multicolumn{4}{|c|}{ Rata-rata } & 150 & 36,86 & 35,86 & 35,71 & 108,43 & 71,71 & Sedang & Tinggi \\
\hline
\end{tabular}

Berdasarkan tabel tersebut, dapat diketahui persentase keterampilan menulis paragraf argumentasi mahasiswa Politeknik Negeri Batam tergolong tinggi, sedang, dan rendah sebagai berikut:

1. Mahasiswa yang berkemampuan tinggi berjumlah 30 orang atau $43 \%$ dari jumlah sampel.

2. Mahasiswa yang berkemampuan sedang berjumlah 26 orang atau $37 \%$ dari jumlah sampel.

3. Mahasiswa yang berkemampuan rendah berjumlah 14 orang atau $20 \%$ dari jumlah sampel.

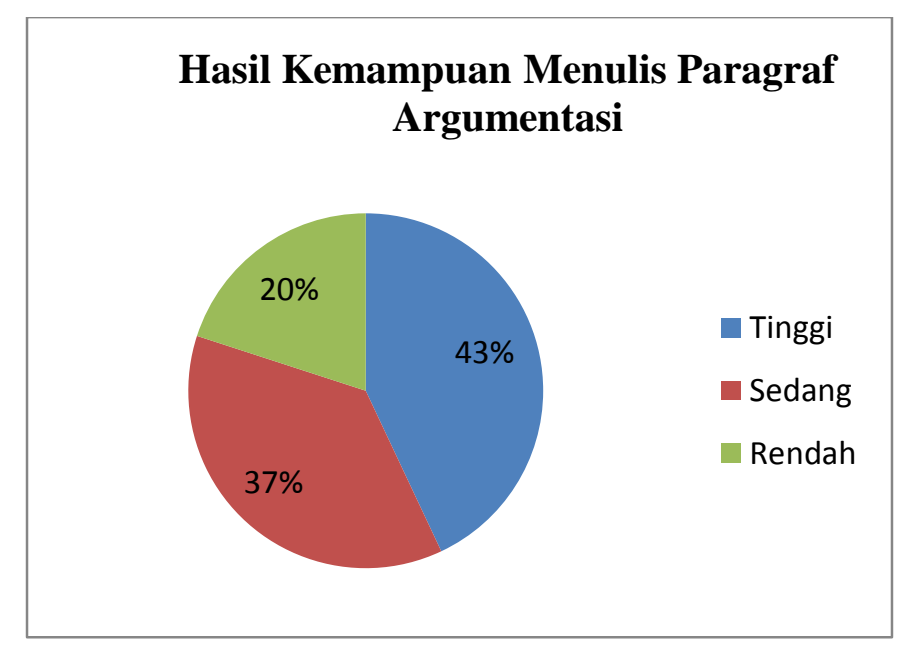

Gambar 1 Hasil Kemampuan Menulis Paragraf Argumentasi

Dengan demikian, hasil penelitian tersebut menunjukkan kemampuan menulis paragraf argumentasi mahasiswa berkategori sedang. Untuk lebih jelas dapat dilihat pada rumus berikut ini:

$$
\begin{array}{rll}
\bar{x} & = & \left(\sum \mathrm{Xi}\right) / \mathrm{n} \\
& = & 5020 / 70 \\
& = & 71,71 \% \text { (dikategorikan sedang) }
\end{array}
$$


Tabel 4. Persentase Keterampilan Menulis Paragraf Argumentasi Mahasiswa di Politeknik Negeri Batam

\begin{tabular}{|c|c|c|c|}
\hline Kualitatif & Kuantitatif & Jumlah & Persentase \\
\hline Tinggi & $80-100$ & 30 & $43 \%$ \\
\hline Sedang & $60-79$ & 26 & $37 \%$ \\
\hline Rendah & $40-59$ & 14 & $20 \%$ \\
\hline \multicolumn{2}{r}{ Jumlah } & 70 & $100 \%$ \\
\hline
\end{tabular}

Berdasarkan tabel di atas dapat diperoleh gambaran tingkat keterampilan menulis karangan argumentasi mahasiswa Politeknik Negeri Batam. Dari 70 mahasiswa yang nilainya berkategori tinggi 30 mahasiswa atau $43 \%$ dari jumlah sampel. Mahasiswa yang memperoleh nilai berkategori sedang 26 mahasiswa atau 37\% dari jumlah sampel. mahasiswa yang mendapat nilai rendah 14 mahasiswa atau 20\% dari jumlah mahasiswa yang ada.

\section{Pembahasan}

Hasil penelitian penulis menunjukkan bahwa keterampilan menulis karangan argumentasi mahasiswa Politeknik Negeri Batam dengan memerhatikan tiga aspek yaitu, kesatuan, kepaduan dan pengembangan paragraf tergolong sedang. Untuk lebih jelasnya, penulis mengurainya sebagai berikut:

1. Kesatuan

Kesatuan adalah semua kalimat yang membina paragraf itu secara bersama-sama menyatakan suatu hal, suatu tema tertentu.

Contoh:

Penebangan hutan harus dihentikan. Pohon-pohon di hutan itu dapat menyerap sisa-sisa pembakaran dari pabrik-pabrik kendaraan bermotor. Karena hutan ditebang habis, maka tidak ada mesin yang menyerap sisa-sisa pembakaran. Sisa-sisa pembakaran dapat meningkatkan pemanasan global, pemanasan global itu akan melelehkan gunung es di kutub. Akibatnya kota-kota di tepi pantai seperti Jakarta, Surabaya, Singapura dan lain-lainnya akan terendam air laut. Jika hutan terus ditebang demi kepentingan ekonomi, maka akan menjadi bahaya yang luar biasa hebatnya.

( Elsa Aisyah Pitmasari)

Paragraf di atas terlihat kesatuan paragraf yang menyatakan satu tema yaitu "Akibat Kerusakan Hutan". Terlepas dari struktur kalimat yang digunakan, paragraf didukung oleh kesatuan. Tidak ada kalimat yang tidak berhubungan dengan gagasan utama. Hubungan antara satu kalimat dengan kalimat lainnya merupakan satu kesatuan yang bulat untuk menunjang gagasan utama.

2. Kepaduan

Kepaduan adalah kekompakan hubungan antara sebuah kalimat dengan kalimat yang membentuk paragraf itu. Contoh:

Dewasa ini, pergaulan bebas sudah menjadi gaya hidup terkini dikalangan remaja khususnya yang hidup di perkotaan. Beberapa ahli mengemukakan bahwa 60\% remaja yang hidup di perkotaan sudah pernah melakukan hubungan suami istri. Hal ini berdasarkan penelitian di beberapa kota besar yang ada di Indonesia. Hal ini tentu saja sangat menghawatirkan bagi masyarakat khususnya para orang tua.

( Arfan Viantiar) 
Berdasarkan contoh paragraf tersebut, dapat dilihat paragraf tersebut menunjukkan adanya kepaduan paragraf. Kalimat utama mengungkapkan gagasan tentang pergaulan bebas sudah menjadi gaya hidup terkini dikalangan remaja khususnya yang hidup di perkotaan. Gagasan tersebut didukung oleh kalimat-kalimat penjelas yang ada di bawahnya secara kompak. Tidak dijumpai kalimat yang menyimpang dari gagasan tersebut maka, kalimat yang satu dengan kalimat yang lain saling berhubungan erat dalam bentuk paragraf tersebut.

\section{Pengembangan}

Suatu paragraf dikatakan berkembang atau lengkap jika berisi kalimat penjelas yang cukup untuk menunjang kejelasan kalimat topik atau kalimat utama.

Contoh:

Al-Quran merupakan sebuah kitab suci bagi umat islam. Al-Quran terdiri dari 30 juz, 114 surat, yang merupakan pedoman bagi umat islam. Namun, pada zaman sekarang ini banyak orang yang sudah tidak mempedulikannya lagi dan hanya menganggap Al-Quran itu hanya sekedar untuk dibaca dan tidak mau untuk mengamalkannya. Hal itu menjadi sebuah berita gembira bagi orang-orang kafir yang menghancurkan Islam dengan cara membakar Al-Quran seperti yang telah terjadi di Amerika Serikat tahun lalu.

(Mega Putri Anastasia)

Dari contoh paragraf tersebut, dapat dilihat paragraf tersebut menunjukkan adanya pengembangan paragaraf. Gagasan dasar tentang Al-Quran merupakan sebuah kitab suci bagi umat Islam terdapat pada kalimat pertama sebagai kalimat topik. Sedangkan gagasan pengembang Al-Quran terdiri dari 30 juz, 114 surat, yang merupakan pedoman bagi umat Islam. Namun, pada zaman sekarang ini banyak orang yang sudah tidak mempedulikannya lagi dan hanya menganggap Al-Quran itu hanya sekedar untuk dibaca dan tidak mau untuk mengamalkannya. Hal itu menjadi sebuah berita gembira bagi orang-orang kafir yang menghancurkan Islam dengan cara membakar AlQuran seperti yang telah terjadi di Amerika Serikat tahun lalu.

Berdasarkan pemaparan pembahasan data penelitian dilihat pada tabel tiga pada rekapitulasi data kemampuan menulis paragraf argumentasi mahasiswa Politeknik Negeri Batam dapat diperoleh rerata 71,71\% . Hasil secara kuantitatif tersebut jika dihubungkan dengan kategori acuan penelitian kualitatif, maka 71,71\% dikategorikan sedang dengan level akses di media sosial sebagai berikut:

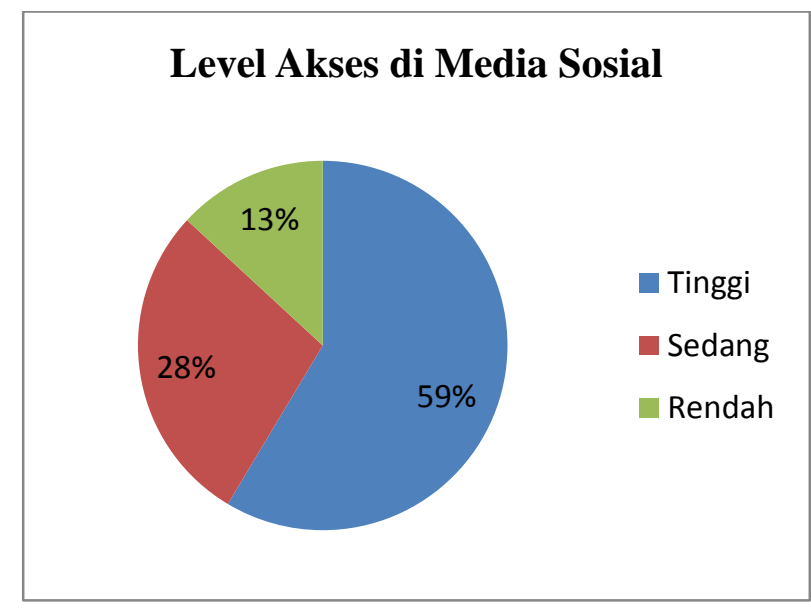

\section{Gambar 2 Level Akses di Media Sosial}

a. Mahasiswa yang berkemampuan tinggi berjumlah 30 orang atau $43 \%$ dari jumlah sampel dengan akses di media sosial $59 \%$. 
b. Mahasiswa yang berkemampuan sedang berjumlah 26 orang atau $37 \%$ dari jumlah sampel dengan akses di media sosial $28 \%$.

c. Mahasiswa yang berkemampuan rendah berjumlah 14 orang atau $20 \%$ dari jumlah sampel dengan akses di media sosial $13 \%$.

Dengan demikian, hasil penelitian menunjukkan dari 70 mahasiswa yang menjadi sampel, dapat diperoleh hasil kemampuan menulis paragraf argumentasi mahasiswa Politeknik Negeri Batam tergolong sedang dengan tingkat akses di media sosial yang tergolong tinggi.

\section{KESIMPULAN}

Menulis paragraf argumentasi merupakan kegiatan yang membuat mahasiswa dapat berargumen, mengeluarkan suatu gagasan dan pendapat yang dibuat dalam sebuah paragraf. Mahasiswa sering menganggap kegiatan menulis adalah tugas yang berat dalam belajar, sehingga diperlukan latihan secara terus-menerus. Hendaknya aktivitas menulis tidak hanya dilakukan pada saat mengerjakan tugas di kampus, tapi menulislah karena itu menjadi kebutuhan bagi setiap mahasiswa.

Tidak dipungkiri kehadiran media sosial berperan penting untuk melatih kemampuan menulis mahasiswa, mahasiswa yang memanfaatkan media sosial setiap harinya untuk diskusi dan sharing justru memiliki kemampuan menulis paragraf yang baik. Berdasarkan penelitian terhadap 70 orang mahasiswa di Politeknik Negeri Batam diperoleh rerata kemampuan menulis paragraf argumentasi berjumlah 71,71\% dikategorikan sedang dengan akses di media sosial yang tinggi.

Berdasarkan hal tersebut dapat disimpulkan bahwa keterampilan menulis bisa dilatih secara terus menerus dengan cara mahasiswa harus banyak membaca, karena dengan membaca mahasiswa akan mendapatkan informasi baru dan pengetahuan mahasiswa akan bertambah. Mahasiswa harus dibiasakan untuk menulis karena dengan menulis mahasiswa akan memiliki ide-ide kreatif yang nantinya bermanfaat untuk orang lain. Perhatikan juga ejaan bahasa Indonesia yang baik dan benar ketika menulis, jangan hanya terpaku pada topik yang menarik untuk dibicarakan tetapi juga perhatikan pilihan kata yang tepat dan ejaan yang benar dari kalimat yang kita tulisakan, dan yang paling penting mahasiswa harus percaya diri dengan apa yang sudah mahasiswa tulis, jangan takut salah tulis karena kesalahan adalah proses pembelajaran.

\section{DAFTAR PUSTAKA}

Arifin, E.Zaenal dan S.Amran Tasai. 2006. Cermat Berbahasa Indonesia untuk Perguruan Tinggi. Jakarta: Grasindo.

Arikunto, Suharsimi. 2006. Prosedur Penelitian Suatu Pendekatan Praktik. Jakrat: PT Rineka Cipta

Charlina dan Mangatur Sinaga 2008. Sanggar Bahasa. Pekanbaru: Cindekia Insani.

Faizah, Hasnah.2007. Mata Kuliah Dasar Umum Bahasa Indonesia. Pekanabru:

Cendikia Insani.

Hakim, Nursal. 2007. Menulis Lanjut. Pekanbaru: Cindikia Insani Pekanbaru. 2007. Keterampilan Dasar Menulis.Pekanbaru: Cendikia Insani Pekanbaru.

Hermandra. 2008. Bahasa Indonesia di Perguruan Tinggi. Pekanbaru: Cendikia Insani Pekanbaru. Indriati, Etty. 2001. Menulis Karya Ilmiah: Artikel, skripsi, Tesis, dan Disertasi. Jakarta: Gramedia 
Keraf, Gorys. 1980. komposisi. Jakarta: Nusa Indah.

.1981. Eksposisi dan Deskripsi. Flores: Nusa Indah.

2005. Argumentasi dan Narasi. Jakarta: PT Gramedia.

Malik, Abdul dkk, 2003. Kemahiran Menulis. Pekanbaru: Unri Press Pekanbaru.

Nasucha, Yakub dkk. 2006. Bahasa Indonesia untuk Penulisan Karya Tulis Ilmiah. Surakarta: Media Perkasa.

Nazir, Mohammad.1998. Metode penelitian. Jakarta: Ghalia Indonesia.

Razak, Abdul. 2000. Membaca Pemahaman Teori dan Aplikasi Pengajaran. Pekanbaru: Autografika. . 2005. Statistik Pengolahan Data Sosial Sistem Manual. Pekanbaru: Yayasan Autografika. 2010. Penelitian Kependidikan. Pekanbaru: Yayasan Autografika.

- 2008. Penelitian Kependidikan Deskripsi, Eksposisi, dan Argumentasi. Pekanbaru: Autografika. SemIi, M.Atar. 1995. Dasar-dasar keterampilan Menulis. Bandung: Angkasa.

Suharto,dan Iryanto. 1996. Kamus Bahasa Indonesia. Surabaya: Indah Surabaya.

Tarigan, Djago. 1997. Kependidikan Keterampilan Berbahasa. Jakarta: Universitas. 1981.Membina Keterampilan Menulis Paragraf dan Pengembangannya.Bandung: Angkasa 